\title{
Determinants of help-seeking behavior in depression: a cross-sectional study
}

\author{
Anke M. Boerema ${ }^{1,2^{*}}$, Annet Kleiboer ${ }^{1,2}$, Aartjan T. F. Beekmann ${ }^{2,3}$, Kim van Zoonen ${ }^{4}$, Henriëtte Dijkshoorn ${ }^{5}$ \\ and Pim Cuijpers ${ }^{1,2}$
}

\begin{abstract}
Background: Although evidence-based and effective treatments are available for people with depression, a substantial number does not seek or receive help. Therefore, it is important to gain a better understanding of the reasons why people do or do not seek help. This study examined what predisposing and need factors are associated with help-seeking among people with major depression.

Methods: A cross-sectional study was conducted in 102 subjects with major depression. Respondents were recruited from the general population in collaboration with three Municipal Health Services (GGD) across different regions in the Netherlands. Inclusion criteria were: being aged 18 years or older, a high score on a screening instrument for depression (K10 > 20), and a diagnosis of major depression established through the Composite International Diagnostic Interview (CIDI 2.1).

Results: Of the total sample, $65 \%(n=66)$ had received help in the past six months. Results showed that respondents with a longer duration of symptoms and those with lower personal stigma were more likely to seek help. Other determinants were not significantly related to help-seeking.

Conclusions: Longer duration of symptoms was found to be an important determinant of help-seeking among people with depression. It is concerning that stigma was related to less help-seeking. Knowledge and understanding of depression should be promoted in society, hopefully leading to reduced stigma and increased help-seeking.
\end{abstract}

Keywords: Depression, Help-seeking, Stigma, Duration of symptoms

\section{Background}

Depression is an important public health issue [1] due to its high prevalence [2], the substantial impact on daily functioning [3], the markedly reduced quality of life in both patients and their relatives [4], and the high economic burden [5]. Effective and evidence-based treatments for depression, like psychotherapy and pharmacological treatments, are available [6]. However, many people do not receive professional care for their symptoms. Estimates of the number of people with depression that receive help

\footnotetext{
* Correspondence: a.m.boerema@vu.nl

'Department of Clinical, Neuro, and Developmental Psychology, Section Clinical Psychology, Faculty of Behavioural and Movement Sciences, Vrije Universiteit Amsterdam, van der Boechorststraat 1, 1081 BT Amsterdam, The Netherlands

${ }^{2}$ EMGO Institute for Health Care and Research, VU University Medical Centre, van der Boechorststraat 7, 1081 BT Amsterdam, The Netherlands Full list of author information is available at the end of the article
}

range from $28 \%$ to $60 \%$ depending on the definition and measurement used [7, 8].

Considering the high burden of depression and the large treatment gap, it is important to identify reasons why people do or do not seek help for depression. This study examined determinants of help-seeking among people with major depression. The study was guided by Anderson's behavioral model of health care utilization [9] which distinguishes three groups of determinants for help-seeking: 1) Predisposing factors: characteristics of individuals that exist prior to their illness, like age or gender; 2) Enabling factors: organizational factors which affect the accessibility of mental health care such as location and distribution of health care facilities. From the patients' perspective this factor relates to knowledge about accessibility of health services and individuals' financial situation; 3) Need factors: professional judgment of people's health status (evaluated need for care) and 
individuals' perspective on health, symptoms and functioning (perceived need for care) [9].

The focus of this study was on predisposing and need factors as several studies have demonstrated that these are dominant in help-seeking [10-12]. In addition, all Dutch residents have basic health insurance which covers health care costs from the general practitioner, primary care, and more specialized psychological care. Therefore, enabling factors are considered less important determinants of help-seeking behavior in the Netherlands.

With respect to 'predisposing factors', demographic factors, social structure, personality and health beliefs are considered to be important in the help-seeking process. Research has shown that people who are younger or middle aged and unmarried are more inclined to use health services for their psychological problems $[10,13]$. Furthermore, intensified health care use is associated with low perceived social support [14] and personality characteristics, especially with high neuroticism $[15,16]$. Other studies identified attitudinal or personal barriers such as the patients' inability to recognize the problem, the belief that depression will abate [11], the desire to handle problems on one's own, [10] and negative beliefs about the effectiveness of treatment [17]. While there is evidence that stigma influences help-seeking adversely, this has not received much attention in Anderson's model [18]. Stigma refers to 'a mark of shame, disgrace or disapproval which results in an individual being rejected, discriminated against, and excluded from participation in a number of different areas of society' [19]. Two different types of stigma are often distinguished: personal and perceived stigma. Personal stigma is defined as peoples' own attitude towards people with depression [20] whereas perceived stigma represents the perception of a persons' belief about how other people think about depression [20]. Personal stigma is common in depression and related to less help-seeking [21, 22].

Regarding 'need factors' in Andersons' behavioral model [9], research has shown that people with depression are more likely to experience a need for treatment when symptoms are severe [23]. Additionally, they were more likely to use health services when they reported a long-term medical condition or physical symptoms or a comorbid anxiety or other mental disorders [24-27].

Despite emerging evidence, it remains unclear why people do or do not seek help, since there is no clear or single decision that determines if and when people seek help [28]. Therefore, it is important to examine predisposing and need factors within the same study. Using data from a general population in the Netherlands, this study examined predisposing (age, partner status, personality, loneliness, personal stigma, perceived stigma) and need factors (severity and duration of complaints, co-morbidity) that are related to help-seeking behavior among people with depression. This study is focused on actual help-seeking and not the intention to seek help. The pathway between going to a health professional and the intention to do this is ambiguous [28] and intentions for help-seeking do not ensure that people will actually seek or receive help for their problems [23, 29].

\section{Methods \\ Participants}

Subjects with major depressive disorder (MDD) were recruited in collaboration with three Municipal Health Services (GGD) across different regions in the Netherlands (Amsterdam, Zoetermeer/Leidschendam, Dordrecht/ Gorinchem). Every four years, the Municipal Health Services conduct a survey, the Health Monitor, in a random sample of the adult population in the Netherlands. The survey includes questions about physical health, psychosocial health, life-style, environment and the K10, a screening questionnaire for psychological distress [30]. Subjects who completed the Health Monitor in 2012 and who scored high on the K10 were invited to participate. A clinical diagnostic interview (CIDI 2.1) was conducted to determine whether subjects met criteria for a current major depressive disorder.

Participants were eligible for inclusion if they: a) had a score of 20 or higher on the screening questionnaire (K10), b) were aged 18 years or older, c) scored positive for a current major depressive disorder or dysthymia measured with the Composite International Diagnostic Interview (CIDI 2.1) in the past six months. People with insufficient understanding of the Dutch language were excluded.

\section{Procedure}

The study was approved by the medical ethical committee of the VUMC (nr 2011/394). Subjects who scored high on the K10 screening questionnaire, and who agreed that they could be approached for further study, were contacted by the Municipal Health Services by post and received an information letter and an informed consent form. Participants were asked to return the informed consent form to the research team at the VU Amsterdam, indicating their willingness to take part. Those that did not respond to this first invitation received one or two reminders.

Next, participants were invited by telephone for the diagnostic interview to determine depression status and were asked to complete an online questionnaire. If preferred, participants were allowed to complete the questionnaire by telephone $(n=14)$ or on paper $(n=1)$.

\section{Instruments}

Depression and anxiety diagnoses were obtained with the CIDI 2.1 interview. Information about age, gender, partner status, psychological distress (K-10), loneliness 
and comorbidity with physical illness was gathered through the 'Health Monitor'. The remaining information was obtained via the online questionnaire.

\section{Help-seeking}

To determine whether participants had received help for depression, a number of questions from the Trimbos/ iMTA questionnaire for Costs associated with Psychiatric Illness (TiC-P) [31] were used. The first part of the Tic-P consists of questions on service use for psychiatric disorders, while the second part is focused on productivity losses [31]. The Tic-P has shown acceptable feasibility and reliability [32].

In the present study the first part of the TiC-P was used. Participants were asked if they had received help for mental health problems from a general practitioner, psychiatrist, psychologist, mental health institution, social worker, clinic for alcohol or drugs abuse, medical specialist, or if they had received day treatment for psychological problems in the past six months. Participants were considered to be "helpseeking" if they confirmed at least one contact with a mental health care provider in the past six months. Participants who did not, were considered to be "non-help-seeking".

\section{Depression and anxiety disorders}

DSM-IV diagnoses were based on the life-time version of the CIDI (version 2.1), a fully structured, standardized questionnaire designed by the World Health Organization (WHO) [33]. It is used to assess mental disorders and provides diagnoses for scientific research [34]. In the present study, anxiety disorders (social anxiety disorder, panic disorder with or without agoraphobia, generalized anxiety disorder) and mood disorders (major depression and dysthymia) were assessed. The CIDI was found to be a reliable instrument [34]. A diagnosis of depression or anxiety in the past 6 months was used to determine a current episode.

All participants were interviewed by professionally trained master level psychology students who worked under supervision.

\section{Determinants of help- seeking}

Demographic information Demographic characteristics that were used in this study were age, gender and partner status.

Social structure Loneliness was measured with the Loneliness scale [35]. The Loneliness scale consists of 11 items. Participants could answer the questions with "yes", "more or less" and "no". A higher score indicates more loneliness. A scale reliability of .80 to .90 is reported in different studies [36]. In this study, the Cronbachs alpha was .87 for the emotional loneliness scale and .85 for the social loneliness scale.

Personality characteristics Neuroticism was assessed with the neuroticism subscale of the NEO- Five Factor Inventory (NEO-FFI) [37]. The NEO-FFI measures five domains of personality: Neuroticism, Extraversion, Openness, Agreeableness and Conscientiousness.

The NEO-FFI neuroticism subscale includes 12 items which can be answered on a 5- point scale, ranging from 'strongly disagree' to 'strongly agree'. Research has reported good internal consistency and test-retest reliability for the NEO-FFI [37]. The internal consistency of Neuroticism in the present study was sufficient (Cronbachs $\alpha=.77$ ).

Stigma Stigma was assessed with the Depression Stigma Scale (DSS) [20]. The DSS consists of two subscales; personal and perceived stigma. The 9 items of each subscale reflect several themes and include status of depression as an illness ('depression is not a real medical illness'), personal control ('people could snap out of depression if they wanted'), character ('sign of weakness'), dangerousness of depression ('people with depression are dangerous') , unpredictability ('people with depression are unpredictable'), shame ('would not tell anyone'), avoidance ('avoid people with depression') and discrimination ('not vote for politician with depression' and 'not employ someone with depression') [20]. The personal stigma subscale is defined as peoples' own attitude towards depression (e.g. 'people with depression are dangerous') [20]. The perceived stigma scale represents the perception of a persons' belief about how other people think about depression (e.g. 'most people believe that people with depression are dangerous') [20]. The items can be valued on a 5-point likert scale ranging from strongly disagree to strongly degree, with a total score range of $0-36$. A higher score indicates more stigma. Moderate to high internal consistency [38-39] and moderate test-retest reliability [20] was reported in several studies. The present study showed moderate to high internal consistency. Cronbach's alpha was .77 for personal stigma and .80 for perceived stigma.

Psychological distress The Kessler-10 (K10) is a brief psychological distress scale [30]. All questions referred to the past month. The K10 is a self-report scale consisting of 10 items that can be valued with a five value response: all of the time, most of the time, a little of the time and none of the time. A higher score indicates more distress. Research support the validity of the K10 as measurement of psychological distress [40]. The internal consistency of the $\mathrm{K}-10$ in the present study was sufficient (Cronbachs $\alpha=.83$ ). 
Symptom duration The duration of symptoms was examined with one question: "How long have you experienced symptoms? (in months)".

Physical illness Information about physical illness was available for the past year. Physical illness included chronical diseases or conditions like, heart conditions, a form of cancer, migraine, high blood pressure, asthma or COPD, dizziness, arthritis or eczema.

\section{Statistical analyses}

Analyses were performed with SPSS 21.0 and a significance level of $p<.05$ was used in all analyses.

A multiple logistic regression analysis was performed to determine the association between the predictors and the dependent variable (help-seeking). The non-helpseeking group was used as the reference group. Six predictors in the analyses were categorical namely: partner status $(0=$ no partner, $1=$ partner $)$, severity of distress $(0=$ mild, $1=$ moderate, $2=$ severe $)$, duration of symptoms $(0=0-12$ months, $1=$ longer than a year ago), loneliness $(0=$ not lonely, $1=$ lonely $)$ and comorbidity with anxiety and physical illness $(0=$ no comorbidity, $1=$ comorbidity). First, we conducted a series of univariable analyses for each predictor separately. Then we conducted a multivariable analysis in which all determinants were included using a backward selection procedure. The assumptions of the logistic regression analyses (linearity of the logit and multicollinearity) were tested and there was no indication of abnormality.

\section{Results}

\section{Study sample}

Information letters were sent to 1191 people who scored high on the K10.

Three hundred thirty-one participants (GGD Amsterdam, $n=140$, GGD Zuid-Holland West, $n=148$, GGD ZuidHolland Zuid, $n=43$ ) returned their informed consent form which is a response rate of $28 \% .291$ participants completed the diagnostic interview (CIDI 2.1). A sample of $n=106$ participants met criteria for MDD. The remaining participants met criteria for subclinical depression and were not included in this paper but reported on elsewhere [41]. A final sample of $n=102$ participants filled in the online questionnaire. Figure 1 describes the flow of participants through the recruitment process.

\section{Characteristics of the study sample}

The sample consisted of 55 women (54\%) and 47 men $(46 \%)$. Respondents were 52 years of age on average (range 20-88). $46 \%$ of the participants reported co-morbidity with an anxiety disorder in the past six months $(n=47)$, $78 \%$ reported co-morbidity with physical symptoms in the past year $(n=77)$. Of the total sample, $65 \%(n=66)$ sought help in the past six months, while $35 \%(n=36)$ did not seek help. Table 1 lists the characteristics of the study sample and provides details of the participants' diagnoses.

\section{Help-seeking}

Of the participants who had received help for psychological problems in the past six months $(n=66), 26 \%(n=17)$ received help in general health care (general practitioner, social work, medical specialist), $15 \%(n=10)$ received help in specialized mental health care (psychiatrist, psychologist, clinic for alcohol or drugs abuse, mental health institution, psychiatrist in hospital). The majority $59 \% \quad(n=39)$ received help in both settings.

Univariable and multivariable logistic regression analyses were conducted to examine the association between helpseeking behavior and determinants among people with a major depressive disorder.

The univariable regression analyses showed significant odds ratios $(\mathrm{OR})$ for duration of symptoms $(\mathrm{OR}=2.60$; $95 \% \mathrm{CI}=1.05-6.41 ; p=0.03)$ and personal stigma $(\mathrm{OR}=$ $0.89 ; 95 \% \mathrm{CI}=0.83-0.96 ; p=0.005)$. After univariable analyses, a backward multivariable analyses was performed to determine the effect of individual predictors controlled for each other. The final model showed significant odds ratios for duration of symptoms $(\mathrm{OR}=$ 2.80; $95 \% \mathrm{CI}=1.06-7.37 ; p=0.03$ ) and personal stigma $(\mathrm{OR}=0.90 ; 95 \% \mathrm{CI}=0.84-0.98 ; p=0.009)$. People who received treatment were more likely to experience a longer duration of symptoms and were less likely to experience personal stigma. Hosmer and Lemeshow Test indicated a good fit of the model $\left(\mathrm{X}^{2}=6.14, p=0.52\right.$, $d f=7$ ). Table 2 displays the results of the univariable and multivariable logistic regression analyses.

\section{Discussion}

The aim of this study was to examine determinants of help-seeking behavior among people with depression by investigating predisposing (age, partner status, personality, loneliness, personal stigma and perceived stigma) and need factors (severity and duration of symptoms, co-morbidity with anxiety or physical illness).

The main finding that duration of symptoms was associated with increased health care utilization, is consistent with previous research $[11,23]$. This finding suggests that people seek help when their symptoms persist for a longer period of time. This is not necessarily an undesirable outcome, as previous research in first onset depressed patients from the community [42] has shown that $50 \%$ remitted within 3 months. This supports the idea of watchful waiting in those with a first episode of depression and a short duration of symptoms. However, this is probably less suitable for people with a chronic or recurrent depression who are at higher risk for long-term impairments and negative consequences from depression [43]. 


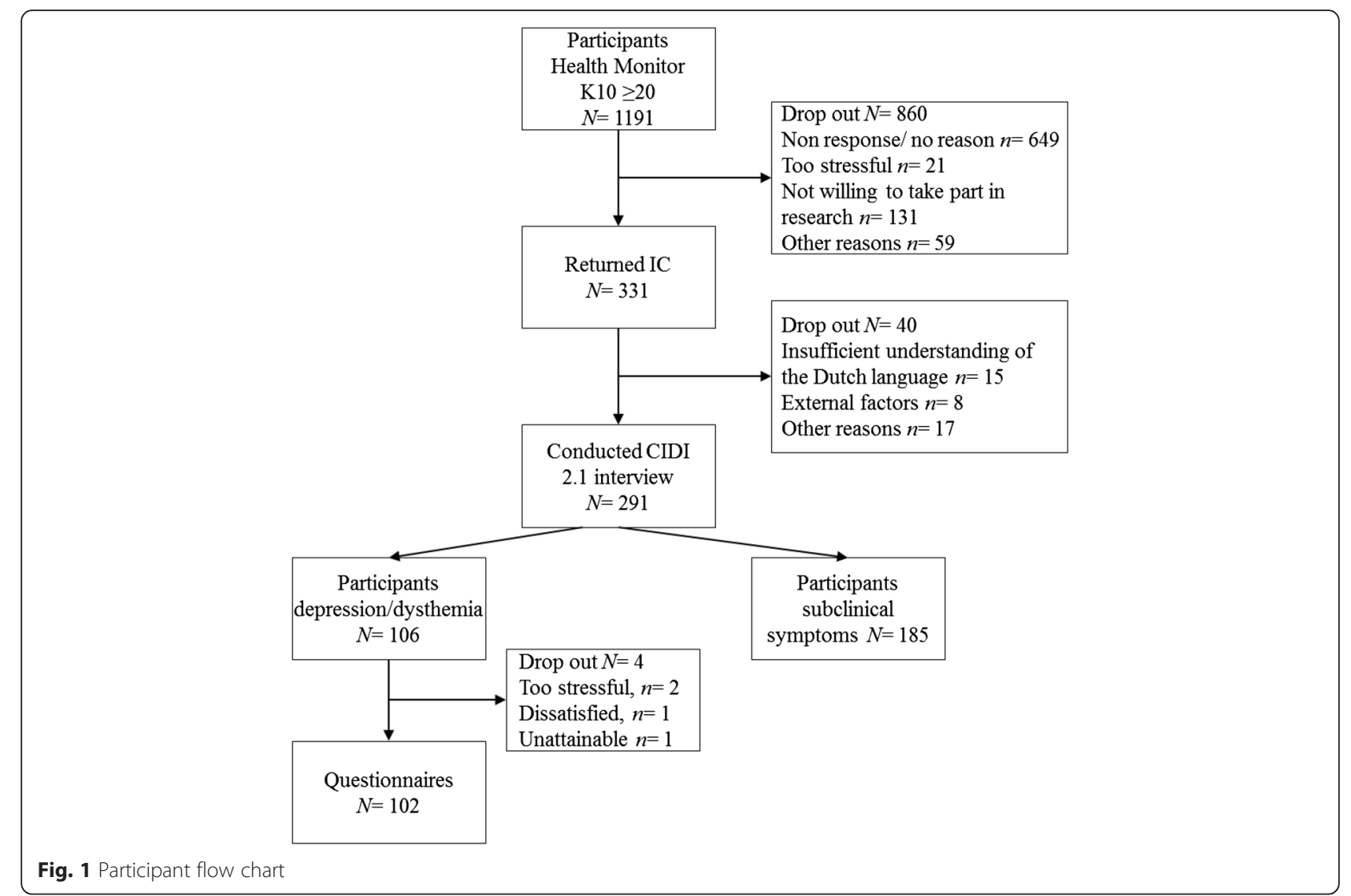

In addition, research has shown that recovery rates for depression declined rapidly after 3 months [42], supporting the idea that long treatment delays may be harmful to patients. More research in people with a first onset of depression and a recurrent form of depression is necessary to investigate the optimal time to seek professional help.

Other need factors, like severity of symptoms and comorbid anxiety, were not related to help-seeking whereas other studies suggest that these factors increase service use in people with depression [24-27]. The direction of the results in the present study are in line with previous findings, however, we may lack statistical power due to a small sample size. Another potential reason why we did not find a relationship between help-seeking and other need factors is that we recruited a group with relatively high comorbidity regarding medical illness and anxiety disorders, suggesting that the need of treatment in both groups is relatively high.

In line with earlier research findings, we found a negative association between personal stigma and help-seeking [29]. In addition, perceived stigma was not associated with help-seeking $[44,45]$. There is some evidence that personal stigma is more important than perceived stigma regarding help-seeking and that these two types of stigma should be considered as separate concepts $[29,40,46]$. A small association between personal stigma and patient's preference to deal with depression alone was found [22]. This suggests that people with higher personal stigma, may be more inclined to handle problems by themselves and are, therefore, less likely to seek professional help.

Other predisposing factors were not related to helpseeking. These results contradict previous research that showed that younger people, those who experience more loneliness, those scoring higher on neuroticism and people who live without a partner are more inclined to use health services $[12,14,16,17]$. This may, again, be explained by the high comorbidity in our sample. There is some evidence that illness severity is a prompt reason to seek help [11] meaning that in people with high comorbidity, predisposing factors may be less important than need factors. Furthermore, there was little difference between the help-seeking and non-help-seeking group with respect to predisposing factors. In addition, the majority of people in both the help-seeking and nonhelp seeking group experienced loneliness, suggesting that other factors than predisposing or need factors are important in this particular group, like for example previous experiences with help-seeking.

This study has several strengths and limitations that need to be considered when interpreting the results. We have recruited participants from a random sample in the general population, which is a strength of this study. 
Table 1 Demographic characteristics for participants that did and did not seek help for depression

\begin{tabular}{|c|c|c|}
\hline & Help-seeking $(N=66)$ & Non-help-seeking $(N=36)$ \\
\hline \multicolumn{3}{|l|}{ Demographics } \\
\hline \multicolumn{3}{|l|}{ Gender, $n(\%)$} \\
\hline Male & $32(49)$ & $15(42)$ \\
\hline Female & $34(51)$ & $21(58)$ \\
\hline Age, mean (SD) & $51.41(17.07)$ & $53.26(17.84)$ \\
\hline \multicolumn{3}{|l|}{ Education, $n(\%)$} \\
\hline Low & $15(23)$ & $10(29)$ \\
\hline Middle & $24(36)$ & $11(30)$ \\
\hline High & $27(41)$ & $14(41)$ \\
\hline \multicolumn{3}{|l|}{ Partner status, $n(\%)$} \\
\hline Partner & $32(49)$ & $21(58)$ \\
\hline No partner & $34(51)$ & $15(42)$ \\
\hline \multicolumn{3}{|l|}{ Psychological distress, $n$ (\%) } \\
\hline Mild & $20(30)$ & $12(34)$ \\
\hline Moderate & $20(30)$ & $9(26)$ \\
\hline Severe & $26(40)$ & $14(40)$ \\
\hline \multicolumn{3}{|l|}{ Co-morbid anxiety disorder, $n(\%)$} \\
\hline No & $33(50)$ & $22(61)$ \\
\hline Yes & $33(50)$ & $14(39)$ \\
\hline \multicolumn{3}{|l|}{ Co-morbid physical illness, $n$ (\%) } \\
\hline No & $12(19)$ & $5(16)$ \\
\hline Yes & $52(81)$ & $27(84)$ \\
\hline \multicolumn{3}{|l|}{ Loneliness, $n$ (\%) } \\
\hline No & $14(21)$ & $5(14)$ \\
\hline Yes & $52(79)$ & $30(86)$ \\
\hline Neuroticism, mean (SD) & $27.7(7.8)$ & $27.0(6.5)$ \\
\hline Personal stigma, mean (SD) & $11.8(5.6)$ & $15.6(5.1)$ \\
\hline Perceived stigma, mean (SD) & $21.1(5.1)$ & $21.3(5.3)$ \\
\hline \multicolumn{3}{|l|}{ Current diagnosis, $n(\%)$} \\
\hline Major depression & $52(79)$ & $30(83)$ \\
\hline Dysthymia & $4(6)$ & $1(3)$ \\
\hline Major depression and dysthymia & $10(15)$ & $5(14)$ \\
\hline \multicolumn{3}{|l|}{ Life-time diagnosis, $n$ (\%) } \\
\hline Lifetime dysthymia, no lifetime MDD & $3(5)$ & $0(0)$ \\
\hline Lifetime MDD, no lifetime dysthymia & $40(61)$ & $23(64)$ \\
\hline Both lifetime MDD and lifetime dysthymia & $23(34)$ & $13(36)$ \\
\hline \multicolumn{3}{|l|}{ Characteristics, mean (SD) } \\
\hline Age onset first episode (8-78) & $36.45(17.43)$ & $36.64(18.10)$ \\
\hline Mean episodes (1-70) & $9.04(13.42)$ & $13.57(16.14)$ \\
\hline \multicolumn{3}{|l|}{ Duration of complaints, $n(\%)$} \\
\hline 0-12 months & $14(21)$ & $14(41)$ \\
\hline 12 months or longer & $52(79)$ & $20(59)$ \\
\hline
\end{tabular}


Table 2 Results univariable logistic model and backward logistic regression multivariable model

\begin{tabular}{|c|c|c|c|c|c|c|c|c|c|}
\hline & \multirow{2}{*}{\multicolumn{3}{|c|}{ Univariable }} & \multicolumn{6}{|c|}{ Multivariable } \\
\hline & & & & \multicolumn{3}{|c|}{ Model $1^{a}$} & \multicolumn{3}{|c|}{ Model $2^{b}$} \\
\hline & $\mathrm{OR}$ & $95 \% \mathrm{Cl}$ & $p$ & $\mathrm{OR}$ & $95 \% \mathrm{Cl}$ & $p$ & $\mathrm{OR}$ & $95 \% \mathrm{Cl}$ & $p$ \\
\hline Age & 0.99 & $0.97-1.01$ & 0.42 & 0.99 & $0.97-1.01$ & 0.42 & & & \\
\hline Partner status & 1.48 & $0.65-3.37$ & 0.34 & 0.76 & $0.27-2.17$ & 0.61 & & & \\
\hline Severity complaints(1) & 1.33 & $0.46-3.86$ & 0.59 & 1.19 & $0.31-.4 .48$ & 0.79 & & & \\
\hline Severity complaints(2) & 1.11 & $0.42-2.92$ & 0.82 & 0.92 & $0.24-3.45$ & 0.90 & & & \\
\hline Duration complaints & $2.60^{c}$ & $1.05-6.41$ & $0.03^{*}$ & 2.59 & $0.80-8.43$ & 0.11 & 2.80 & $1.06-7.37$ & $0.03^{*}$ \\
\hline Comorbidity anxiety & 1.57 & $0.68-3.58$ & 0.28 & 1.28 & $0.38-4.28$ & 0.68 & & & \\
\hline Comorbidity physical & 0.80 & $0.25-2.51$ & 0.70 & 0.96 & $0.25-3.78$ & 0.96 & & & \\
\hline Neuroticism & 1.01 & $0.95-1.07$ & 0.63 & 0.98 & $0.90-1.07$ & 0.98 & & & \\
\hline Loneliness & 0.61 & $0.20-1.88$ & 0.39 & 0.59 & $0.15-2.36$ & 0.45 & & & \\
\hline Personal stigma & $0.89^{\mathrm{d}, \mathrm{e}}$ & $0.83-0.96$ & $0.005^{*}$ & 0.91 & $0.83-0.99$ & $0.04^{*}$ & 0.90 & $0.84-0.98$ & $0.009^{*}$ \\
\hline Perceived stigma & 0.99 & $0.91-1.07$ & 0.85 & 0.98 & $0.88-1.09$ & 0.77 & & & \\
\hline
\end{tabular}

Model $(X 2=11.92, p=0.009, d f=2)$. Note. OR = odds ratio, $\mathrm{Cl}=$ confidence interval, *Significant at .05

${ }^{a}$ Model 1 represents the first model

${ }^{\mathrm{b}}$ Model 2 represents the final model

${ }^{c}(x 2=4.31, p=0.03, d f=1)$

${ }^{\mathrm{d}}$ Controlled for three residuals that seem to influence the model

${ }^{\mathrm{e}}(\mathrm{x} 2=6.39, p=0.01, d f=1)$

However, the participation rate was relatively low, $28 \%$. Furthermore, not all respondents to the Health Monitor gave permission to be contacted for further research which may have led to an additional selection bias. We do not have information on subjects who did not want to participate in the Health Monitor or this study. However, compared to other studies (NEMESIS) [47], our sample was relatively old, had a chronic course of depression and high comorbidity. Therefore, they may have other questions, ideas and expectations concerning help-seeking than people with a first episode of depression, who are often younger and have less comorbidity. For example, research has shown that people with chronic depression have more questions on how to prevent another episode, while people with a first time episode ask for more information about how to cope with depression in daily life [48]. Furthermore, people with a chronic depression may be more demoralized and have negative expectations about the outcome of treatment, which may influence their willingness to seek help [48]. Although the nature of our sample can be considered a limitation in some respect, depression is known to have a recurrent and chronic nature $[42,49]$ and there is not much research that examines reasons to seek help among people with chronic depression. Another limitation of this study was the relatively small sample size which may have limited the statistical power. A final limitation of this study was the cross-sectional design, meaning that no conclusions about causality can be drawn.

\section{Conclusions}

This study suggests that duration of symptoms and personal stigma are associated with help-seeking behavior among people with depression. Previous research has shown that depression is less stigmatized compared with other mental health disorders like schizophrenia [50]. However, this study showed that personal stigma is also related to help-seeking behavior among people with depression. More attention is needed to increase awareness about symptoms of depression to reduce personal stigma. Stigma interventions, such as educational programs, are associated with a small but significant reduction of personal stigma [20, 51]. Hopefully, such programs will lead to increased knowledge and more understanding of depression and subsequently increased help-seeking behavior.

\section{Availability of data and materials}

Data available on request.

\section{Competing interests}

The authors declare that they have no competing interests.

\section{Authors' contributions}

$A B$ worked the analyses and wrote the first draft of the paper. $P C, K Z, A K, A B$ helped designing the study and have been involved in revising the manuscript. HD was involved in the process of recruitment within the GGD Amsterdam and has been involved in revising the manuscript. All authors contributed to and have approved the final manuscript.

\section{Acknowledgements}

The researchers would like to thank the Municipal Public Health Services (GGD) for their effort in the recruitment of the participants in this study and providing the data of the K10, age, gender, partner status, loneliness and physical illness in the current study. 


\section{Funding}

This study was funded by ZonMW grant number 50-51510-98-009, but was not involved in data collection, analysis, interpretation of the data, writing the report or the decision to submit this article.

\section{Author details}

'Department of Clinical, Neuro, and Developmental Psychology, Section Clinical Psychology, Faculty of Behavioural and Movement Sciences, Vrije Universiteit Amsterdam, van der Boechorststraat 1, 1081 BT Amsterdam, The Netherlands. ${ }^{2}$ EMGO Institute for Health Care and Research, VU University Medical Centre, van der Boechorststraat 7, 1081 BT Amsterdam, The Netherlands. ${ }^{3}$ Department of Psychiatry, VU University Medical Centre, van der Boechorststraat 7, 1081 BT Amsterdam, The Netherlands. ${ }^{4}$ Statistics Netherlands (CBS), Henri Faasdreef 312, 2492 JT Den Haag, The Netherlands. ${ }^{5}$ GGD Amsterdam, Nieuwe Achtergracht 100, 1018 WT Amsterdam, The Netherlands.

Received: 11 December 2014 Accepted: 21 March 2016

Published online: 23 March 2016

\section{References}

1. Mathers CD, Loncar D. Projections of global mortality and burden of disease from 2002 to 2030. PLoS Med. 2006. doi:10.1371/journal.pmed.0030442.

2. Steel Z, Marnane C, Iranpour C, Chey T, Jackson JW, Patel V, et al. The global prevalence of common mental disorders: a systematic review and meta-analysis 1980-2013. Int J Epidemiol. 2014;43:476-93.

3. Eaton WW, Martins SS, Nestadt G, Bienvenu J, Clarke D, Aleandre P. The burden of mental disorders. Epidemiol Rev. 2008;30:1-14.

4. Saarni SI, Suvisaari J, Sintonen H, Pirkola S, Koskinen S, Aromaa A, et al. Impact of psychiatric disorders on health-related quality of life: general population survey. Br J Psychiatry. 2007. doi:10.1192/bjp.bp.106.025106.

5. Wang PS, Simon G, Kessler RC. The economic burden of depression and the cost-effectiveness of treatment. Int J Methods Psychiatr Res. 2003;12:22-33.

6. Cuijpers P, Straten van A, Driessen E, Oppen van P, Bockting C, Andersson G. Depression and dysthymic disorders. In: Sturmey P, Hersen M, editors. Handbook of Evidence-Based Practice in Clinical Psychology. Hoboken: John Wiley and Sons; 2012. p. 243-84.

7. Bristow K, Patten S. Treatment-seeking rates and associated mediating factors among individuals with depression. Can J Psychiatr. 2002;47:660-5.

8. Bebbington $\mathrm{P}$, Brugha $T$, Meltzer $\mathrm{H}$, Jenkins $\mathrm{R}$, Ceresa $\mathrm{C}$, Farrell $M$, et al. Neurotic disorders and the receipt of psychiatric treatment. Int Rev Psychiatry. 2003;15:108-14.

9. Andersen RM. Revisiting the behavioral model and access to medical care: does it matter? J Health Soc Behav. 1995;36:1-10.

10. Andrade LH, Alonso J, Mneimneh Z, Wells JE, Al-Hamzawi A, Borges G, et al. Barriers to mental health treatment: results from the WHO World Mental Health surveys. Psychol Med. 2013;44:1303-17.

11. Thompson A, Hunt C, Issakidis C. Why wait? Reasons for delay and prompts to seek help for mental health problems in an Australian clinical sample. Soc Psychiatry Psychiatr Epidemiol. 2004;39:810-7.

12. Verhaak PF, Prins MA, Spreeuwenberg P, Draisma S, van Balkom TJ, Bensing JM, et al. Receiving treatment for common mental disorders. Gen Hosp Psychiatry. 2009. doi:10.1016/j.genhosppsych.2008.09.011.

13. Bijl RV, Ravelli M. Psychiatric morbidity, service use, and need for care in the general popuation: results of the Netherlands Mental Health Survey and Incidence Study. Am J Public Health. 2000;90:602-7.

14. ten Have M, Vollebergh W, Bijl R, Ormel J. Combined effect of mental disorder and low social support on care service use for mental health problems in the Dutch general population. Psychol Med. 2002;32:311-23.

15. Kotov R, Gamez W, Schmidt F, Watson D. Linking "big" personality traits to anxiety, depressive, and substance use disorders: a meta-analysis. Psychol Bull. 2010. doi:10.1037/a0020327.

16. ten Have M, Oldehinkel A, Vollebergh W, Ormel J. Does neuroticism explain variations in care service use for mental health problems in the general population? Results from the Netherlands Mental Health Survey and Incidence Study (NEMESIS). Soc Psychiatry Psychiatr Epidemiol. 2005. doi:10.1007/s00127-005-0916-z.

17. Beljouw IMJ, Verhaak PFM, Cuijpers P, van Marwijk HWJ, Penninx BWJH. The course of untreated anxiety and depression, and determinants of poor one-year outcome: a one-year cohort study. BMC Psychiatry. 2010;10:1-10.
18. Clement S, Schauman O, Graham T, Maggioni S, Evans-Lacko N, Bezborodovs $C$, et al. What is the impact of mental health-related stigma on help-seeking? A systematic review of quantitative and qualitative studies. 2014. doi:10.1017/ S0033291714000129.

19. World Health Organization. The World health report: Mental health: new understanding, new hope. Geneva: World Health Organization; 2001.

20. Griffiths KM, Christensen H, Jorm AF, Evans K, Groves C. Effect of web-based depression literacy and cognitive behavioural therapy interventions on stigmatising attitudes to depression. Randomised controlled trial. Br J Psychiatry. 2004; 185:342-9.

21. Schomerus G, Auer C, Rhode D, Luppa M, Freyberger HJ, Schmidt S. Personal stigma, problem appraisal and perceived need for professional help in currently untreated depressed persons. J Affect Disord. 2012. doi:10.1016/j.jad. 2012.02.022

22. Griffiths KM, Crisp DA, Jorm AF, Christensen H. Does stigma predict a belief in dealing with depression alone? J Affect Disord. 2011. doi:10.1016/j.jad.2011.03.012.

23. Sherwood C, Salkovskis PM, Rimes KA. Help-seeking for depression: the role of beliefs, attitudes and mood. Behav Cogn Psychother. 2007. doi:10.1017/S1352465807003815.

24. Mojtabai R, Olfson M, Mechanic D. Perceived need and help-seeking in adults with mood, anxiety, or substance use disorders. Arch Gen Psychiatry. 2002;59:77-84

25. Roy-Byrne PP, Stang P, Wittchen HU, Ustun B, Walters EE, Kessler RC Lifetime panic-depression comorbidity in the National Comorbidity Survey. association with symptoms, impairment, course and help-seeking. $\mathrm{Br} \mathrm{J}$ Psychiatry. 2000;176:229-35.

26. Wang J, Patten SB, Williams JV, Currie S, Beck CA, Maxwell CJ, et al. Help-seeking behaviours of individuals with mood disorders. Can J Psychiatry. 2005;50(10):652-9.

27. ten Have $M$, de Graaf $R$, Vollebergh W, Beekman A. What depressive symptoms are associated with the use of care services? Results from the Netherlands Mental Health Survey and Incidence Study (NEMESIS). J Affect Disord. 2004. doi:10.1016/s0165-0327(03)00132-0.

28. Schomerus G, Angermeyer MC. Stigma and its impact on help-seeking for mental disorders: what do we know? Epidemiol Psichiatr Soc. 2008;17:31-7.

29. Barney $\sqcup$, Griffiths KM, Jorm AF, Christensen H. Stigma about depression and its impact on help-seeking intentions. Aust N Z J Psychiatry. 2006;40:51-4.

30. Kessler R, Andrews G, Colpe L, Hiripe E, Mroczek D, Normand S, et al. Short screening scales to monitor population prevalences and trends in non-specific psychological distress. Psychol Med. 2002. doi:10.1017/S0033291702006074.

31. Hakkaart-van Roijen L, Straten van A, Donker M, Tiemens B. Handleiding Trimbos/ iMTA questionnaire for Costs associated with Psychiatric Illness. Rotterdam: Instituut voor Medische Technology Assessment, Erasmus MC; 2002.

32. Bouwmans $C$, Jong DK, Timman R, Zijlstra-Vlasveld M, van der Feltz CC, Swan Tan S, et al. Feasibility, reliability and validity of a questionnaire on healthcare consumption and productivity loss in patients with a psychiatric disorder (TiC-P). BMC Psychiatry. 2013;13:1-9.

33. Robins LN, Wing J, Wittchen HU, Helzer JE, Babor TF, Burke J, et al. The Composite International Diagnostic Interview. An epidemiologic instrument suitable for use in conjunction with different diagnostic systems and in different cultures. Arch Gen Psychiatry. 1988:45:1069-77.

34. Wittchen HU. Reliability and validity studies of the WHO-Composite International Diagnostic Interview (CIDI): a critical review. J Psychiatr Res. 1994;28:57-84.

35. De Jong Gierveld J, Amphuis FH. The development of a Rasch-type loneliness-scale. Appl Psychol Meas. 1985;9:289-99.

36. Gierveld DJ, van Tilburg T. Manual of the loneliness scale. Amsterdam: Department of Social Research Methodology; 1999.

37. Hoekstra HA, Ormel J, De Fuyt F. Big Five persoonlijkheidskenmerken, Handleiding [Big Five personality characteristics. Manual of the Dutch Version of the NEO-PI-R/NEO-FFI]. Lisse: Swets and Zeitlinger; 1996.

38. Calear AL, Griffiths KM, Christensen H. Personal and perceived depression stigma in Australian adolescents: magnitude and predictors. J Affect Disord. 2011;129:104-8.

39. Griffiths KM, Christensen $\mathrm{H}$, Jorm AF. Predictors of depression stigma. BMC Psychiatry. 2008:8:1-12.

40. Andrews G, Slade T. Interpreting scores on the Kessler Psychological Distress Scale. Aust N Z J Public Health. 2001:25:494-7.

41. van Zoonen K, Kleiboer AM, Beekman ATF, Smit JH, Boerema AM, Cuijpers P. Reasons and determinants of help-seeking in people with a subclinical depression. J Affect Disord. 2014;173:105-12. 
42. Spijker J, de Graaf R, Bijl RV, Beekman AT, Ormel J, Nolen WA. Duration of major depressive episodes in the general population: results from The Netherlands Mental Health Survey and Incidence Study (NEMESIS). Br J Psychiatry. 2002;181:208-13.

43. Burcusa SL, lacono WG. Risk for recurrence in depression. Clin Psychol Rev. 2007. doi:10.1016/j.cpr.2007.02.005.

44. Schomerus $\mathrm{G}$, Matschinger $\mathrm{H}$, Angermeyer MC. The stigma of psychiatric treatment and help-seeking intentions for depression. Eur Arch Psychiatry Clin Neurosci. 2009. doi:10.1007/s00406-009-0870-y.

45. Golberstein E, Eisenberg D, Gollust SE. Perceived stigma and mental health care seeking. Psychiatr Serv. 2008:59:392-9.

46. Brohan E, Gauci D, Sartorius N, Thornicroft G. Self-stigma, empowerment and perceived discrimination among people with bipolar disorder or depression in 13 European countries: the GAMIAN-Europe study. J Affect Disord. 2011. doi:10.1016/j.jad.2010.09.001.

47. de Graaf R, ten Have M, van Dorsselear S. De psychische gezondheid van de Nederlandse bevolking. NEMESIS-2: Opzet en eerste resultaten. [The psychological health of the Dutch population]. Trimbos Instituut: Utrecht; 2010.

48. Geleuken van A. Patiëntenperspectief op depressie [Patients' perspective on depression]. In: Handbook Depressieve stoornissen [Handbook Depressive Disorder]. Utrecht: De Tijdstroom; 2008. p. 81-8.

49. Hardeveld F, Spijker J, de Graaf R, Nolen WA, Beekman ATF. Prevalence and Predictors of recurrence of major depressive disorder in adult population. Acta Psychiatr Scand. 2010;122:184-91.

50. Crisp A, Gelder AG, Rx S, Meltzer HI, Rowlands OJ. Stigmatisation of people with mental illnesses. Br J Psychiatry. 2000;177:4-7.

51. Griffiths KM, Carron-Arthur B, Parsons A, Reid R. Effectiveness of programs for reducing the stigma associated with mental disorders. A meta-analysis of randomized controlled trials. World Psychiatry. 2014. doi:10.1002/wps.20129.

\section{Submit your next manuscript to BioMed Central and we will help you at every step:}

- We accept pre-submission inquiries

- Our selector tool helps you to find the most relevant journal

- We provide round the clock customer support

- Convenient online submission

- Thorough peer review

- Inclusion in PubMed and all major indexing services

- Maximum visibility for your research

Submit your manuscript at www.biomedcentral.com/submit 